\title{
The real challenge to free will and responsibility
}

\section{Maureen $\mathrm{Sie}^{1}$ and Arno Wouters ${ }^{2}$}

${ }^{1}$ Department of Philosophy, Erasmus University Rotterdam, P.O. Box 1738, 3000 DR Rotterdam, The Netherlands

${ }^{2}$ Heyendaal Institute, Radboud University Nijmegen, P.O. Box 9103, 6500 HD Nijmegen, The Netherlands

Adina Roskies [1] argues that recent developments in the neurosciences do not challenge our ideas of free will and personal responsibility. She limits her discussion, however, to 'libertarian free will', and her argument focuses on the idea that we are able to act differently from how we choose to act. She does not address the influential new compatibilist views of free will and responsibility (see Box 1). These views, we contend, are most significantly challenged by recent discoveries.

According to new compatibilists, it is crucial to our practice of personal responsibility that we are 'practically rational' beings, able to act for reasons, i.e., to figure out what should or should not be done and act accordingly [2]. It is this capacity to act for reasons that matters when we blame or praise one another, not libertarian free will. For example, I am held responsible if I steal something from a shop, but not if I am a kleptomaniac, a three-year old child, or simply did not realize that the item I took should be paid for (thinking it was just a sample). The last case is not properly described as 'stealing'; the reason I took the item was that I thought it was free. In the other two cases my practical rationality was either impaired or not yet fully developed.

Thus new compatibilists connect personal responsibility with practical rationality. It is exactly our common understanding of practical rationality that is challenged by our growing understanding of how the brain works. Recent developments in the behavioral, cognitive, and neurosciences indicate that, more often than not, we act in an automatic and unaware fashion, making up reasons only as we go along [3]. We are not directly aware of what drives our actions but infer reasons on the basis of a priori causal theories, confabulating them if we cannot find reasonable explanations $[4,5]$. So many causal factors escape consciousness that confabulation seems the rule rather than the exception [6]. Even our moral judgments seem based on intuitions that are not, or are only partially, accessible to introspection. The reasons we come up with to justify these judgments are post-hoc rationalizations that played no role in their generation [7].

It remains to be seen how best to interpret these findings. However, at the very least, they make clear that we cannot take our practice of giving and asking for reasons at face value and hold on to the idea that we have a simple to observe capacity to act for reasons. Ironically, the belief that it is obvious and uncontroversial that we act for reasons (and clear what we mean by this phrase) was precisely what made the new compatibilist views so popular in philosophy: the metaphysically problematic concept of libertarian free will could be replaced with the unproblematic, mundane 'responsiveness to reasons'. In light of recent discoveries, 'responsiveness to reasons' proves an equivocal notion that needs thorough rethinking. This is the real challenge to our common concept of free will and responsibility. 


\section{Box 1. New Compatibilism}

The relation between determinism and libertarian free-will is one of the oldest and most frequently discussed problems in philosophy. However, a dominant line of thought in contemporary philosophy has put aside the determinism issue. According to these new compatibilists the existence of alternative possibilities is irrelevant to our judgments about responsibility [8]. For example, if I witness a crime and do not warn the police out of lack of interest or concern, the fact that I could not have warned them becauseunknown to me-my phone has been disconnected, is irrelevant. What we refer to when we talk about 'free will' is that we stand in an authoritative relationship to what we do or leave undone: that we 'agree with', 'accept', or 'positively endorse' it [9]. We do not act out of our own free will when this relation is frustrated, e.g. when we act out of compulsion, addiction, or 'only because' we had no other alternative. The details of this view remain subject to controversy, but it is generally agreed that personal responsibility depends on our ability to act on the basis of our deliberations (i.e. for reasons), rather then on the existence of alternative ways of acting.

\section{References}

1 Roskies, A. (2006) Neuroscientific challenges to free will and responsibility. Trends in Cognitive Sciences 10, 419-423

2 Fischer, J.M., and Ravizza, M. (1999) Responsibility and Control: A Theory of Moral Responsibility. Cambridge University Press

3 Bargh, J.A., and Chartrand, T.L. (1999) The Unbearable Automaticity of Being. American Psychologist July 54, 462-479

4 Nisbett, R.E., and Wilson, T.D. (1977) Telling More Than We Can Know: Verbal Reports on Mental Processes. Psychological Review 84, 231-259

5 Wegner, D.M. (2002) The Illusion of Conscious Will. MIT Press

6 Wilson, T.D. (2004) Strangers to Ourselves: Discovering the Adaptive Unconscious. Belknap

7 Haidt, J. (2001) The Emotional Dog and Its Rational Tail: A Social Intuitionist Approach to Moral Judgment. Psychological Review 108, 814-834

8 Frankfurt, H. (1969) Alternative Possibilities and Moral Responsibility. Journal of Philosophy 66, 829-839

9 Frankfurt, H. (1971) Freedom of the Will and the Concept of a Person. Journal of Philosophy 68, 5-20 